\title{
Effect of packaging materials on the shelf-life of strawberry cv. Sweet Charlie under room temperature storage
}

\author{
A. K. Panda*, R. K. Goyal, A. K. Godara and Vikas Kumar Sharma \\ Department of Horticulture, CCS Haryana Agricultural University, Hisar- 125004 (Haryana), INDIA \\ *Corresponding author. E-mail: asish.panda014@gmail.com \\ Received: November 14, 2015; Revised received: April 27, 2016; Accepted: July 21, 2016
}

\begin{abstract}
Strawberry (Fragaria $\times$ ananassa Duch.) fruits Cv. Sweet Charlie were harvested at the $3 / 4^{\text {th }}$ maturity stage. Freshly harvested fruits were packed in plastic punnets and wrapped with different packaging materials viz., low-density polyethylene (LDPE) 25, 50 and 75 micron, polypropylene (PP) 25 micron, cellophane paper and cling film. Effect of all the packaging materials was studied in ambient storage condition $\left(18-25{ }^{\circ} \mathrm{C}\right.$ and $\left.80-90 \% \mathrm{RH}\right)$. The result showed that LDPE 50 micron packaging material proved as the most effective one to control the weight loss $(5.49 \%)$ and all of the LDPE films along with the PP and cling films appeared best to minimize decay loss. MAP conditions help prevent the decaying of strawberry fruits up to a day. The total soluble solids $(6.35 \%-5.78 \%)$ and titratable acidity $(0.91 \%-0.70 \%)$ were found to be decreased with the prolongation of storage periods, but no significant variation was recorded for different packaging materials. A better level of ascorbic acid in strawberry fruits packed with LDPE $50(31.56 \mathrm{mg} / 100 \mathrm{~g})$ and 75 micron $(29.86 \mathrm{mg} / 100 \mathrm{~g})$ packaging films was retained. The organoleptic rating of strawberry fruits was found best in fruits packed with LDPE 50 micron (7.90) packaging films. In future, these experimental results may prove very useful for storage of strawberry fruits for a certain period in better quality.
\end{abstract}

Keywords: Packaging materials, Quality, Room temperature, Shelf life, Strawberry

\section{INTRODUCTION}

India is a country bestowed with a wide climatic diversity. Owing to that diversity most of the well-known fruits i.e., either temperate or tropical or subtropical, are found in India. Among the different temperate fruits, strawberry (Fragaria $\times$ ananassa Duch.) is a popular one, which has successfully been acclimatized in the subtropics as well. It is one of the most attractive, delicious, refreshing and nutritious soft fruit and mostly preferred for its delicate flavour. The edible portion of the fruit is about $98 \%$ and contains various nutritionally important elements. It is popular among the red fruits and a rich source of anthocyanin possessing high antioxidant activity (Sun et al., 2002).

Strawberry shows non-climacteric ripening behavior. The rate of ethylene evolution is low but due to its characteristic high respiration rate $(50-100 \mathrm{ml} \mathrm{CO} 2$ per $\mathrm{kg}$ of fruits per hour at $20{ }^{\circ} \mathrm{C}$ ), it is a highly perishable fruit and can be stored only for a very short period (Nuneset al., 2006). This characteristic feature of strawberry fruit limits its popularity among the growers as well as the traders. About 20-50 per cent fruit loss occurs as post-harvest decay in strawberry depending upon harvesting month, fruit maturity, transportation distance and method of packaging (Mingchi and Kojimo, 2005).

Packaging is an integral and determinant part of the industrial and commercial food supply chain. To have a better shelf life of the packed product as well as to attract the consumers, the packaging material plays a significant role. Modified atmospheric packaging (MAP) using different films can be illustrated as one of the best and low cost technology to have a better shelf life with proper quality for a soft fruit like strawberry. Modified atmosphere (MA) means an atmospheric composition around the fruit that is different from that of normal air i.e., 78.08 per cent $\mathrm{N}_{2}, 20.95$ per cent $\mathrm{O}_{2}$ and 0.03 per cent $\mathrm{CO}_{2}$ (Kader, 1992). Such change in the gaseous atmosphere can be attributed to the factors like respiration and other biochemical processes of the produce and permeation of gases through the packaging film. It slows down the growth of aerobic microbes and the speed of oxidation reactions. A well-known benefit of MAP is to reduce high water loss by creating high humidity inside the packaging and with that the produce maintains freshness comparatively for a longer period. Therefore, present investigation was carried out to evaluate the shelf life of stored fruits of strawberry (Fragaria $\times$ ananassa Duch.) cv. Sweet Charlie under room temperature storage in modified atmospheric packaging.

\section{MATERIALS AND METHODS}

Experimental site and material: The present study was conducted in the Post-Harvest Laboratory of Department of Horticulture, CCS Haryana Agricultural University, Hisar during March 2015. Medium sized fruits of strawberry cv. Sweet Charlie were harvested 
at approximately 75 per cent colour development stage in early morning hours (6-8 am). About $150 \mathrm{~g}$ fruits were packed in plastic punnets with due care to minimize the chances of injury. Individual punnets were wrapped with different packaging materials viz., Low density polyethylene (LDPE) 25 micron, 50 micron and 75 micron, Polypropylene (PP) 25 micron, Cling Film, Cellophane Paper and then sealed. Fruits kept in punnets without any packaging material wrapping was taken as control in the experiment.

Quality analysis: All the packages were stored under the ambient condition and various physic-chemical observations related to the quality of the stored fruits were recorded daily with three replications. The loss in weight during storage was calculated by subtracting the final weight from the initial weight of the fruits and expressed in per cent. The decay loss was calculated by subtracting the number of decayed fruit from the total number of fruits and expressed in per cent. The total soluble solids of preserved fruits and pulp were determined at room temperature by using Pocket Digital Refractometer having a range of 0 to $32^{\circ}$ Brix by putting a drop of juice obtained by pressing the pulp on the prism and taking the readings. Acidity and ascorbic acid were determined as per the method suggested by AOAC (1990) and stored fruits of strawberry were subjected to sensory evaluation by a panel of six judges following the 9 points hedonic rating scale for colour, flavor, appearance and texture. Characters with mean scores of 6 or more out of 9 marks were considered acceptable.

Statistical analysis: The data were analyzed according to the procedure for analysis of completely randomized design (CRD) as given by Panse and Sukhtme (1984). The overall significance of difference among the treatments was tested, using critical differences (C.D.) at $5 \%$ level of significance. The results were statistically analyzed with the help of a windows based computer package OPSTAT (Sheoran, 2004).

\section{RESULTS AND DISCUSSION}

Loss in weight (\%): The data illustrated in the Table 1 revealed that there was no significant loss in weight of strawberry fruits on the $1^{\text {st }}$ and $2^{\text {nd }}$ day of storage. On the $3^{\text {rd }}$ and $4^{\text {th }}$ day LDPE 50 micron recorded least loss in weight as compared to all other (LDPE 25 micron, 75 micron, PP 25 micron, Cling film, Cellophane pa-

Table 1. Effect of packaging materials on loss in weight (\%) of strawberry cv. Sweet Charlie under room temperature storage.

\begin{tabular}{lcccc}
\hline \multirow{2}{*}{ Treatments } & \multicolumn{4}{c}{ Storage period (days) } \\
\cline { 2 - 5 } & $\mathbf{1}$ & $\mathbf{2}$ & $\mathbf{3}$ & $\mathbf{4}$ \\
\hline LDPE 25 micron & 1.64 & 2.84 & 4.31 & 6.42 \\
LDPE 50 micron & 1.18 & 2.31 & 3.69 & 5.49 \\
LDPE 75 micron & 1.31 & 2.49 & 3.96 & 5.87 \\
PP 25 micron & 1.44 & 2.78 & 4.16 & 6.29 \\
Cling film & 1.82 & 3.04 & 4.58 & 6.69 \\
Cellophane paper & 1.96 & 3.22 & 4.71 & 6.84 \\
Control & 2.11 & 3.51 & 5.78 & 9.02 \\
CD $(\mathrm{P}=0.05)$ & $\mathrm{NS}$ & $\mathrm{NS}$ & 0.18 & 0.31 \\
\hline
\end{tabular}

per and the control one) i.e., 3.69 and 5.49 per cent, respectively. The loss in weight of fruits varied for different packaging materials. Minimum per cent loss in weight was recorded in fruits packed with LDPE 50 micron packaging film. Packaging films alter the $\mathrm{CO}_{2}$ and $\mathrm{O}_{2}$ concentration inside the packages hence, in a high respiring fruit like strawberry the respiration rate is reduced by keeping in low $\mathrm{O}_{2}$ and/or high $\mathrm{CO}_{2}$ atmosphere (El-Kazzaz et al., 1983 and Li and Kader, 1989). Fruits packed in different packaging films recorded lower weight loss, which was obvious due to their role in checking rate of transpiration/respiration and maintaining higher humidity inside the wrappers (Ben, 1985). On the other hand, fruits retained unwrapped conditions exhibited the highest physiological loss in weight as compared to fruits packed in films and that might be due to the exposure of fruit surface to the open atmosphere resulting in higher rate of transpiration and respiration thereby leading to higher physiological loss in weight. Similarly, Kumar and Nagpal (1996) in mango, Siddiqui and Gupta (1997) in guava and Sonkar and Nagpal (1998) in Nagpur mandarin also reported the fruits wrapped in different packaging films retain better quality for longer duration compared to the unwrapped fruits.

Decay loss (\%) : The data pertaining to decay loss of the strawberry fruits stored under room temperature condition $\left(18-25^{\circ} \mathrm{C}\right)$ was illustrated in the Table 2 . No decay loss was found on the $1^{\text {st }}$ day of storage, on the $2^{\text {nd }}$ day of storage there was no significant variation among the different packaging materials. On $3^{\text {rd }}$ day of storage, a lower decay loss was recorded in LDPE 50 (1.73\%), 25 micron (1.77\%), PP 25 micron (1.77\%), cling film (1.83\%) and LDPE 75 micron (1.89\%) packaging as that of the cellophane paper wrapping $(2.13 \%)$ and the unwrapped punnets $(3.45 \%)$. On the $4^{\text {th }}$ day of storage, the minimum decay loss $3.16 \%$ was recorded in LDPE 50 micron packaging, which was at par to the LDPE 75 micron (3.26\%) and the cling film

Table 2. Effect of packaging materials on decay loss (\%) of strawberry cv. Sweet Charlie under room temperature storage.

\begin{tabular}{lccc}
\hline \multirow{2}{*}{ Treatments } & \multicolumn{3}{c}{ Storage period (days) } \\
\cline { 2 - 4 } & $\mathbf{2}$ & $\mathbf{3}$ & $\mathbf{4}$ \\
\hline \multirow{2}{*}{ LDPE 25 micron } & 1.00 & \multirow{2}{*}{$1.77(3.33)$} & 3.74 \\
& $(0.00)$ & & $(13.33)$ \\
& 1.00 & $1.73(3.03)$ & 3.16 \\
LDPE 50 micron & $(0.00)$ & & $(12.12)$ \\
& 1.00 & $1.89(4.17)$ & 3.26 \\
LDPE 75 micron & $(0.00)$ & & $(12.50)$ \\
& 1.00 & $1.77(3.33)$ & 4.17 \\
PP 25 micron & $(0.00)$ & & $(16.67)$ \\
& 1.00 & $1.83(3.70)$ & 3.93 \\
Cling film & $(0.00)$ & & $4.81)$ \\
Cellophane pa- & 1.73 & $2.13(6.06)$ & $(18.18)$ \\
per & $(3.03)$ & & 5.01 \\
Control & 1.83 & $3.45(14.81)$ & $(25.93)$ \\
CD (P=0.05) & $(3.70)$ & & 0.52 \\
\hline
\end{tabular}


Table 3. Effect of packaging materials on total soluble solids ( Brix) of strawberry cv. Sweet Charlie under room temperature storage.

\begin{tabular}{lcccccc}
\hline \multirow{2}{*}{ Treatments } & \multicolumn{7}{c}{ Storage period (days) } & \multirow{2}{*}{ Mean } \\
\cline { 2 - 6 } & $\mathbf{0}$ & $\mathbf{1}$ & $\mathbf{2}$ & $\mathbf{3}$ & $\mathbf{4}$ & \\
\hline LDPE 25 micron & 6.33 & 6.40 & 6.33 & 6.25 & 5.83 & 6.23 \\
LDPE 50 micron & 6.37 & 6.47 & 6.35 & 6.20 & 5.97 & 6.27 \\
LDPE 75 micron & 6.40 & 6.44 & 6.34 & 6.30 & 5.80 & 6.26 \\
PP 25 micron & 6.31 & 6.43 & 6.36 & 6.27 & 5.78 & 6.23 \\
Cling film & 6.30 & 6.41 & 6.35 & 6.25 & 5.74 & 6.21 \\
Cellophane paper & 6.38 & 6.43 & 6.28 & 5.87 & 5.72 & 6.14 \\
Control & 6.33 & 6.44 & 6.21 & 5.98 & 5.63 & 6.12 \\
Mean & 6.35 & 6.43 & 6.32 & 6.16 & 5.78 & \\
CD (P=0.05) & Treatments (T) $=$ NS, Storage period (S) $=0.10, \mathrm{~T}$ \\
\hline
\end{tabular}

Table 5. Effect of packaging materials on ascorbic acid (mg/100g) of strawberry cv. Sweet Charlie under room temperature storage

\begin{tabular}{|c|c|c|c|c|c|c|}
\hline \multirow{2}{*}{ Treatments } & \multicolumn{5}{|c|}{ Storage period (days) } & \multirow{2}{*}{ Mean } \\
\hline & $\mathbf{0}$ & 1 & 2 & 3 & 4 & \\
\hline LDPE 25 micron & 36.43 & 33.95 & 29.49 & 25.00 & 19.87 & 28.95 \\
\hline LDPE 50 micron & 38.57 & 35.80 & 32.05 & 28.29 & 23.08 & 31.56 \\
\hline LDPE 75 micron & 37.14 & 34.57 & 30.77 & 26.32 & 20.51 & 29.86 \\
\hline PP 25 micron & 38.57 & 34.57 & 29.49 & 24.34 & 19.31 & 29.26 \\
\hline Cling film & 37.86 & 33.95 & 28.85 & 23.03 & 21.59 & 29.06 \\
\hline Cellophane paper & 36.43 & 32.10 & 26.92 & 22.31 & 17.38 & 27.03 \\
\hline Control & 37.14 & 31.48 & 25.21 & 20.63 & 14.18 & 25.73 \\
\hline Mean & 37.45 & 33.77 & 28.97 & 24.27 & 19.42 & - \\
\hline $\mathrm{CD}(\mathrm{P}=0.05)$ & \multicolumn{6}{|c|}{$\begin{array}{c}\text { Treatments }(\mathrm{T})=2.21, \text { Storage period }(\mathrm{S})=2.41, \mathrm{~T} \times \mathrm{S} \\
=\mathrm{NS}\end{array}$} \\
\hline
\end{tabular}

$(3.45 \%)$ packaging. Positive effects of film packaging are the maintenance of high relative humidity and reduction in water loss of produce at optimum temperature and these conditions are responsible for lowering the spoilage of fruits (Hardenburg, 1971). However, in the present study the lowest decay loss (\%) was reported in strawberry fruits packed with the packaging films in all the storage conditions. Modified atmospheric packaging prevented the occurrence of decayed loss in the packed strawberry fruits up to a single day. Different packaging films behaved differentially to regulate the fruit decay on different days under different storage conditions. This might be due to the property of packaging films to retain a higher level of $\mathrm{CO}_{2}$ inside the packages. Higher atmospheric $\mathrm{CO}_{2}$ level shows fungi static effect (Li and Kader, 1989). Similar findings were reported by Ozkaya et al. (2009), they also found the modified atmospherically packed strawberry fruits resulted in a lower decay loss than the control fruits (without packaging).

Total soluble solids ( ${ }^{\circ}$ Brix): The TSS of strawberry fruits packed in different packaging materials exhibited significant variation (at 5\% level) with respect to the period of storage only, but no significant variation was recorded with respect to the type of packaging films used. Under room temperature condition (Table 3), the TSS was maximum on the $1^{\text {st }}$ day $\left(6.43^{\circ}\right.$ Brix $)$, being at par the $0^{\text {th }}$ day $\left(6.35{ }^{\circ}\right.$ Brix $)$ of storage and but decreased gradually till $4^{\text {th }}$ day $\left(5.78^{\circ}\right.$ Brix $)$ of storage. Similarly, Maga-
Table 4. Effect of packaging materials on titratable acidity (\%) of strawberry cv. Sweet Charlie under room temperature storage.

\begin{tabular}{lcccccc}
\hline \multirow{2}{*}{ Treatments } & \multicolumn{7}{c}{ Storage period (days) } & \multirow{2}{*}{ Mean } \\
\cline { 2 - 6 } & $\mathbf{0}$ & $\mathbf{1}$ & $\mathbf{2}$ & $\mathbf{3}$ & $\mathbf{4}$ & \\
\hline LDPE 25 micron & 0.86 & 0.86 & 0.83 & 0.80 & 0.74 & 0.82 \\
LDPE 50 micron & 0.93 & 0.90 & 0.86 & 0.83 & 0.77 & 0.86 \\
LDPE 75 micron & 0.90 & 0.86 & 0.86 & 0.83 & 0.80 & 0.85 \\
PP 25 micron & 0.96 & 0.90 & 0.83 & 0.77 & 0.74 & 0.84 \\
Cling film & 0.90 & 0.86 & 0.83 & 0.70 & 0.67 & 0.79 \\
Cellophane paper & 0.83 & 0.80 & 0.74 & 0.67 & 0.61 & 0.73 \\
Control & 0.96 & 0.80 & 0.70 & 0.64 & 0.58 & 0.74 \\
Mean & 0.91 & 0.85 & 0.81 & 0.75 & 0.70 & - \\
CD (P=0.05) & Treatments (T) $=$ NS, Storage period $(\mathrm{S})=0.05, \mathrm{~T} \times \mathrm{S}$ \\
\hline
\end{tabular}

Table 6. Effect of packaging materials on organoleptic rating of strawberry cv. Sweet Charlie under room temperature storage.

\begin{tabular}{lcccccc}
\hline \multirow{2}{*}{ Treatments } & \multicolumn{9}{c}{ Storage period (days) } & Mea \\
\cline { 2 - 6 } & $\mathbf{0}$ & $\mathbf{1}$ & $\mathbf{2}$ & $\mathbf{3}$ & $\mathbf{4}$ & $\mathbf{n}$ \\
\hline LDPE 25 micron & 7.50 & 8.22 & 8.53 & 7.51 & 6.53 & 7.66 \\
LDPE 50 micron & 7.50 & 8.21 & 8.52 & 8.12 & 7.13 & 7.90 \\
LDPE 75 micron & 7.50 & 8.20 & 8.50 & 7.97 & 6.80 & 7.79 \\
PP 25 micron & 7.50 & 8.23 & 7.07 & 6.52 & 5.34 & 6.93 \\
Cling film & 7.50 & 8.35 & 8.44 & 7.29 & 6.13 & 7.54 \\
Cellophane paper & 7.50 & 8.16 & 6.95 & 6.28 & 5.15 & 6.81 \\
Control & 7.50 & 8.03 & 6.48 & 5.13 & 4.17 & 6.26 \\
Mean & 7.50 & 8.20 & 7.78 & 6.97 & 5.89 & - \\
\hline
\end{tabular}

zine et al. (2015) and Li and Kader (1989) also reported, strawberry fruits packed in LDPE in room storage retain the TSS per cent compared to the other packaging material. TSS of strawberry fruits increased up to a short period of storage and then a steady decrease was observed. The initial rise in TSS might be attributed to the completion of ripening process of the unripe fruits. The decrease in TSS in the later phase of storage might be due to the on -going physiological catabolic processes in the fruits.

Titratable acidity (\%): The titratable acidity of strawberry fruits packed in different packaging films went on decreasing with the advancement of storage period. Under room temperature storage condition (Table 4), no significant variation in titratable acidity of fruits packed with different packaging films was found, however, over the storage period, significant variation (at 5\% level of significance) in titratable acidity was observed. Maximum titratable acidity was noted on the $0^{\text {th }}$ day $(0.91 \%)$ and minimum on the $4^{\text {th }}(0.70 \%)$ day of storage. The interaction between the packaging films and storage periods was not-significant. Similar trend in decrease in the acidity of strawberry fruit over a storage period was observed by Garcia et al. (1998), Kirad et al. (2007) and Shood et al. (2012). Such reduction in acidity might be due to the utilisation of different free acids present in the vacuole of cells during various metabolic processes like respiration and anthocyanin biosynthesis (Wooward, 1972). In the present study, the variation in titratable acidity of strawberry fruits as a function of various packaging materials, which was not significant. The present result is in close agreement with the findings of $\mathrm{Li}$ and Kader (1989) and Magazin et al. (2015), who also observed the non-significant variation in the per cent acidity in strawberry, when packed in different packaging materials. 
Ascorbic acid (mg/100g): The data recorded during the period of study revealed that the ascorbic acid content of strawberry fruits packed in different packaging films varied significantly (at 5\% level of significance) over the period of storage. Under the room temperature storage (Table 5), maximum ascorbic acid was recorded in fruits packed with LDPE 50 micron packaging film $(31.56 \mathrm{mg} / 100 \mathrm{~g})$, which was at par the fruits wrapped with LDPE 75 micron $(29.86 \mathrm{mg} / 100 \mathrm{~g})$ and minimum in fruits kept unwrapped as well as packed in cellophane paper. With the advancement of storage periods, ascorbic acid decreased significantly (at 5\% level of significance). It acid was recorded maximum on the $0^{\text {th }}$ day $(37.45 \mathrm{mg} / 100 \mathrm{~g})$ and minimum on $4^{\text {th }}$ day $(19.42 \mathrm{mg} / 100 \mathrm{~g})$ of storage. The interaction among the packaging materials and storage periods was statistically not-significant. Such results might be attributed to better modification of the atmosphere inside the packages by these materials with respect to the $\mathrm{O}_{2}$ concentration and concomitant decrease in enzymatic oxidation of ascorbic acid (Agrahari et al., 2001). Over the prolongation of the storage period, the ascorbic acid content was on a decreasing trend. This might be due to the oxidation and irreversible conversion of ascorbic acid to dehydro-ascorbic acid in the presence of enzyme ascorbinase. Similar decreasing trend in ascorbic acid content was obtained by Kirad et al. (2007) with packaging of fruits.

Organoleptic rating: The organoleptic rating of the stored strawberry fruits packed in different packaging materials differed. Under the room temperature storage (Table 6), fruits packed in LDPE 50 micron packaging film illustrated the highest organoleptic rating (7.90). The minimum (6.26) rating was given to the fruits kept unwrapped. On the $1^{\text {st }}$ day (8.20) of storage, fruits had the maximum and on the $4^{\text {th }}$ day (5.89) the minimum organoleptic rating.Among the different packaging materials, LDPE 50 micron illustrated the best organoleptic rating of stored fruits. This might be attributed to the characteristic feature of this film having a proper balance for the permeability of $\mathrm{CO}_{2}, \mathrm{O}_{2}$ and $\mathrm{RH}$, which maintained a better overall sensory quality in strawberry fruits. Although having an initial rise during storage, the overall sensory quality of strawberry fruits followed a decreasing trend. These findings are in close aggregation with the earlier findings of Garcia et al. (1998) and Shood et al. (2012), they observed fruits packed in different packaging films maintained acceptability for longer period as compared to un-wrapped fruits.

\section{Conclusion}

The present study concluded that strawberry is a highly perishable fruit, which cannot be stored for a longer period but different wrapping treatments maintained the qualitative characteristics of stored fruits at room temperature condition. From the day, first onwards the loss in weight of fruits was observed but LDPE 50 micron packaging material proved as the most effective one to control the weight loss. MAP conditions prevented decaying of strawberry fruits up to single day under the room temperature condition. The TSS, titratable acidity, ascorbic acid and organoleptic ratings decreased in the stored fruit at room temperature and spoiled completely after $4^{\text {th }}$ day of storage. At the room temperature condition the LDPE 50 micron may prove very useful for storage of strawberry fruits for longer duration in better quality.

\section{ACKNOWLEDGEMENTS}

The assistance and help received from the Indian Council of Agricultural Research (Junior Research fellowship to the corresponding author) and the CCSHAU, Hisar during the course of study have been fully acknowledged.

\section{REFERENCES}

A.O.A.C. (1990). Official Methods of Analysis $12^{\text {th }}$ Ed. Association of Official Analytical Chemist, Washington, D.C. USA.

Agrahari, P.R., Thakur, K.S., Sharma, R.M., Tripathi, V.K. and Singh, R.R. (2001). Effects of various packaging treatments and storage atmosphere on storage quality of Chandler strawberry (Fragaria $\times$ ananassa Duch.). Scientia Hort., 7: 63-74.

Ben, Y. (1985). Individual seal packaging of fruits and vegetables in plastic films- a new post-harvested technique. Hort Sci., 94: 524-528.

El-Kazzaz, M.K., Sommer, N.F. and Fortlage, R.J. (1983). Effect of different atmospheres on post-harvest decay and quality of fresh strawberries. Phytopathology., 73: 282-285.

Garcia, J.M., Medina, R.J., Olias, J.M. (1998). Quality of strawberries automatically packed in different plastic films. $J$. Food Sci., 63(6): 1037-41.

Hardenburg, R.E. (1971). Effect of in-package environment on keeping quality of fruits and vegetables. Hort Sci., 6: 178.

Kader, A.A. (1992). Modified atmosphere during transport and storage. In Postharvest Technology and Quality of Strawberries. J. American Soc. Hort. Sci., 114: 629-634.

Kirad, K.S., Barche, S., Dash, A. and Sharma R.K. (2007). Responses of different packaging materials and chemicals on the shelf life of strawberry (Fragaria $\times$ ananassa Duch.) and correlation between different traits. Acta Hort., 746: 89-95.

Kumar, R. and Nagpal, R. (1996). Effect of post-harvest treatment on the storage behavior of mango cv. Dusehri. Haryana J. hortic. Sci., 25: 101-108.

Li, C., and Kader, A.A. (1989). Residual effects of controlled atmospheres on postharvest physiology and quality of strawberries.J. American Soc. Hort. Sci., 114: 629-634.

Magazine, N., Keserovic, Z., Cabilovski, R., Milic, B., Doric, M. and Manojlovic, M. (2015). Modified atmosphere packaging of full ripe strawberries. Acta Hort., 1071: 241-244.

Mingchi, L. and Kojimo, T. (2005). Study on fruit injury susceptibility of strawberry grown under different soil moisture to storage and transportation. J. Fruit Sci., 22: 
A. K. Panda et al. / J. Appl. \& Nat. Sci. 8 (3): 1290 - 1294 (2016)

238-242.

Nunes, M.C.N, Brecht, J.C., Morais, A.M. and Sargent, S.A. (2006). Physiochemical changes during strawberry development in the field compared with those that occur in harvested fruits during storage. J. Sci. Food and Agric., 1: 180-190.

Ozkaya, O., Dundar, O., Scovazzo, G.C. and Volpe, G. (2009). Evaluation of quality parameters of strawberry fruits in modified atmospheric packaging during storage. African J. Biotech., 8(5):789-793.

Panse, V.G. and Sukatme, P.V. (1967). Statistical methods for Agricultural workers. Indian Council of Agricultural Research, New Delhi, pp. 155.
Sheoran, O.P. (2004). Statistical package for Agricultural Research workers, CCS HAU, Hisar.http://hau.ernet.in.

Siddiqui, S. and Gupta, O.P. (1997). Effect of individual fruit wrapping by different materials on the shelf life of Guava cv. Allahabad Safeda.Haryana J. hortic. Sci., 26 (1-2): 101-104.

Sonkar, R.K. and Ladaniya, M.S. (1998). Effect of tray over wrapping by heat shrinkable and stretchable films on Nagpur mandarin fruits. Indian Food Packer, 52(5): 22-26.

Sun, J., Chu, Y.F., Wu, X., and Liu, R.H. (2002). Antioxidant and anti-proliferative activities of common fruits. J. Agric. Food Chem., 50: 7449-7454. 